\title{
CLASSIFICATION OF DUAL-WAVELENGTH AIRBORNE LASER SCANNING POINT CLOUD BASED ON THE RADIOMETRIC PROPERTIES OF THE OBJECTS
}

\author{
M. Pilarska ${ }^{1}$ \\ ${ }^{1}$ Warsaw University of Technology, Faculty of Geodesy and Cartography - magdalena.pilarska@pw.edu.pl
}

Commission II, WG II/3

KEY WORDS: airborne laser scanning, LiDAR, multispectral laser scanning, classification, OPALS, GNDVI

\begin{abstract}
:
Airborne laser scanning (ALS) is a well-known and willingly used technology. One of the advantages of this technology is primarily its fast and accurate data registration. In recent years ALS is continuously developed. One of the latest achievements is multispectral ALS, which consists in obtaining simultaneously the data in more than one laser wavelength. In this article the results of the dualwavelength ALS data classification are presented. The data were acquired with RIEGL VQ-1560i sensor, which is equipped with two laser scanners operating in different wavelengths: $532 \mathrm{~nm}$ and $1064 \mathrm{~nm}$. Two classification approaches are presented in the article: classification, which is based on geometric relationships between points and classification, which mostly relies on the radiometric properties of registered objects. The overall accuracy of the geometric classification was $86 \%$, whereas for the radiometric classification it was $81 \%$. As a result, it can be assumed that the radiometric features which are provided by the multispectral ALS have potential to be successfully used in ALS point cloud classification.
\end{abstract}

\section{INTRODUCTION}

Airborne laser scanning (ALS) (Baltsavias, 1999) is a willingly used technology in remote sensing. The ALS data provide user with accurate geometric information about registered objects. The major advantage of this technology is its fast and accurate data acquisition. Additionally, ALS data enables to generate among all digital terrain model (DTM), digital surface model (DSM), and even 3D city models (Wehr and Lohr, 1999). The ALS technology is continuously developed. In recent years, multispectral laser scanning has become more popular among remote sensing specialists (Bakuła, 2015). Multispectral laser scanning is a technique which consists in acquiring the data in more than one laser wavelength simultaneously. Concerning the airborne laser scanning, the laser systems are able to register the data in three wavelengths: $532 \mathrm{~nm}, 1064 \mathrm{~nm}$ and $1550 \mathrm{~nm}$. It is hard to apply some laser wavelengths for long rage ALS because of the power of the signals and their eye-safety (Pfenningbauer \& Urlich, 2011). The dual-wavelength laser systems are above all equipped with green and infrared scanners. These sensors are mostly bathymetric systems, which are dedicated among all to coastal zone and shallow water mapping (Doneus et al., 2015; Irish and Lillycrop, 1999). Thanks to integration of the laser scanners which register data in infrared and green wavelength, it is possible to obtain both topographic and bathymetric information. First multispectral laser system, which provides data in three wavelengths $(532 \mathrm{~nm}, 1064 \mathrm{~nm}$ and $1550 \mathrm{~nm})$, is Titan by Optech (van Rees, 2015). Lately Riegl company launched into the market a dual-wavelength system: Riegl VQ-1560i-DW.

The main advantage of multispectral laser scanning over aerial images is that laser scanning provides information in shadowed areas. This advantage is significant while concerning the urban areas with high buildings, which are the main reason of shadows occurrence on aerial images. Additionally, multispectral laser scanning can substitute for the previous conducted passive aerial images integration with single-wavelength ALS.
If data are registered in more than one wavelength, extended radiometric information about objects is registered. This makes the multispectral ALS data more valuable and raises the possible applications. When the infrared scanner is combined with the green one, such systems can be applicable in archaeology, e.g. for shallow-water bodies bathymetric lasers makes is possible to map the underwater topography and to look for the archaeological remains there (Doneus et al., 2015). Multispectral laser scanning show a considerable potential in vegetation analysis. Dual-wavelength and multispectral laser scanners can be used for calculation of the green normalized difference vegetation index (green NDVI). Multispectral LiDAR provides users with information about vegetation and the distribution of the physiological processes, what enables to understand the periodical changes in carbon content better (Wallace et al., 2012). In Axelsson et al. (2018) structural and spectral features from multispectral ALS for tree species classification were examined. The result showed that spectral data provides a better basis for tree species classification than structural features.

Multispectral LiDAR can be also applied in land cover classification (Yan and Shaker, 2014). Most of the approaches based on rasterized point cloud and further raster classification (Bakuła et al., 2016). The application of multispectral ALS in automatic map updating was proposed by Matikainen et al. (2016). In Wichmann et al. (2015) two step point cloud classification was presented, in which automatic geometric classification was supported with spectral information about particular classes. For this purpose histograms presenting the distribution of intensity values for individual classes were analysed.

As mentioned above, intensity which is registered within the laser scanning, especially the multispectral LiDAR, have found various applications. However, the intensity values are influenced by various factors such as range, incidence angle and terrain topology. Therefore, the registered intensity values have to be previously corrected in order to minimize the influence of external factor (Pilarska, 2016). Different intensity correction 
methods have been proposed in literature. In some of the methods only range correction is applied (Matikainen et al., 2017), whereas in another methods more factors are included (Kaasalainen et al., 2011). In Yan and Shaker (2014) Gaussian Mixture Modelling (GMM) was applied for decreasing intensity differences between overlapping strips.

The main purpose of the experiment presented in this article is to perform the classification of dual-wavelength airborne laser scanning data based on the radiometric properties of the registered objects. The classification results were compared to single-wavelength classification and TerraScan geometric classification. These studies play an important role, because multispectral laser scanning is a rapidly developing technology, which will certainly found many applications in photogrammetry and remote sensing (e.g. urban mapping, vegetation analysis). Additionally, the dual-wavelength classification which was used in this approach, is mostly based in the radiometric properties of single echoes and no specially dedicated algorithms were used.

\section{STUDY DATA}

In the experiment ALS data were used, which were acquired with dual-wavelength RIEGL VQ-1560i. This sensor is equipped with two laser scanners: green one $(532 \mathrm{~nm})$ and infrared one (1064 $\mathrm{nm})$. The flight mission was conducted in Warsaw, on 30 July 2016. The medium point density of the data acquired with each of the scanners was 12 point per $\mathrm{m}^{2}$. As a result, the approximate point density of the dual -wavelength data is 24 point per $\mathrm{m}^{2}$.

The study area was chosen so that it encompassed different kind of object. Additionally, there is some denivelation on the right part of the area under the trees.

\section{CLASSIFICATION METHODOLOGY}

The data which were used in the experiment, required some preprocessing. At the beginning radiometric correction of the data was performed in order to remove the influence of the scan angle on the registered intensity values. The correction was conducted according to Matikainen et al (2017). Thus, the following formula was used:

$$
i_{\text {corr }}=i * \frac{R_{i}^{2}}{R_{r e f}^{2}}
$$

where $\quad i=$ registered intensity

$i_{\text {corr }}=$ corrected intensity values

$R_{\text {ref }}=$ flying altitude

$R_{i}=$ distance between the scanner and registered object

Further, the data from green and infrared scanners were combined. The data were combined so that for each echo of one scan the intensity from the nearest echo from the second scan was stored as additional attribute. As a result, for every echo as Red attribute the corrected intensity obtained in near infrared wavelength was stored and as Green - corrected intensity in green wavelength. As a Blue band Green Normalized Difference Vegetation Index (GNDVI) was assigned. This index was calculated for every echo from intensity registered in infrared and green wavelengths, according to the equation (2):

$$
G N D V I=\frac{N I R-G}{N I R+G}
$$

where $\quad N I R=$ intensity in near infrared wavelength $G=$ intensity in green wavelength
As a result, visualization of the point cloud as intensity RGB composition could be provided (Fig. 1). According to the Figure 1 it can be noticed that registered objects differ from each other considering the radiometric properties of the objects. The biggest difference that be noticed occurs between vegetation and other objects like roads and buildings. Because of these noticeable radiometric differences, both between the objects and within the objects (e.g. trees, buildings), it is worth to exploit the potential of the data which are intensities registered in two wavelength. One of the possible applications of the data is point cloud classification. In this experiment the data were classified in two programmes: TerraScan application and OPALS (Pfeifer et al, 2014). TerraScan is the main application in the Terrasolid Software. OPALS is a modular program system, which is developed by the research group Photogrammetry from the Department of Geodesy and Geoinformation of Technical University Wien. Classification in TerraScan was conducted based on the geometric properties of the data, with the usage of the algorithms implemented in TerraScan. In this software the manual classification of the data was also conducted and was further used as a reference in the classification accuracy assessment.

\section{RGB composition}
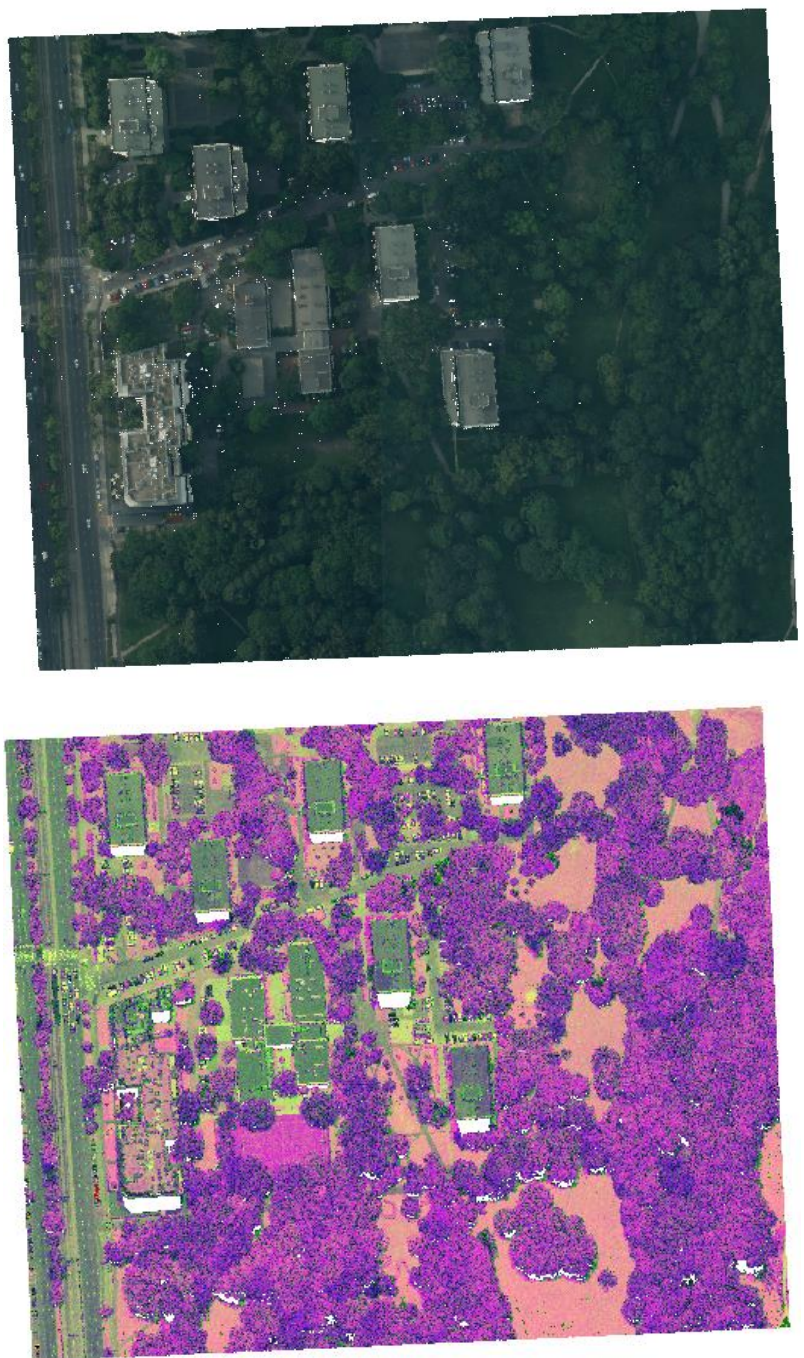

Fig. 1 Top view of the point cloud presented as RGB composition, where Red is intensity registered in near infrared, Green - in green and Blue band corresponds with the GNDVI values. 


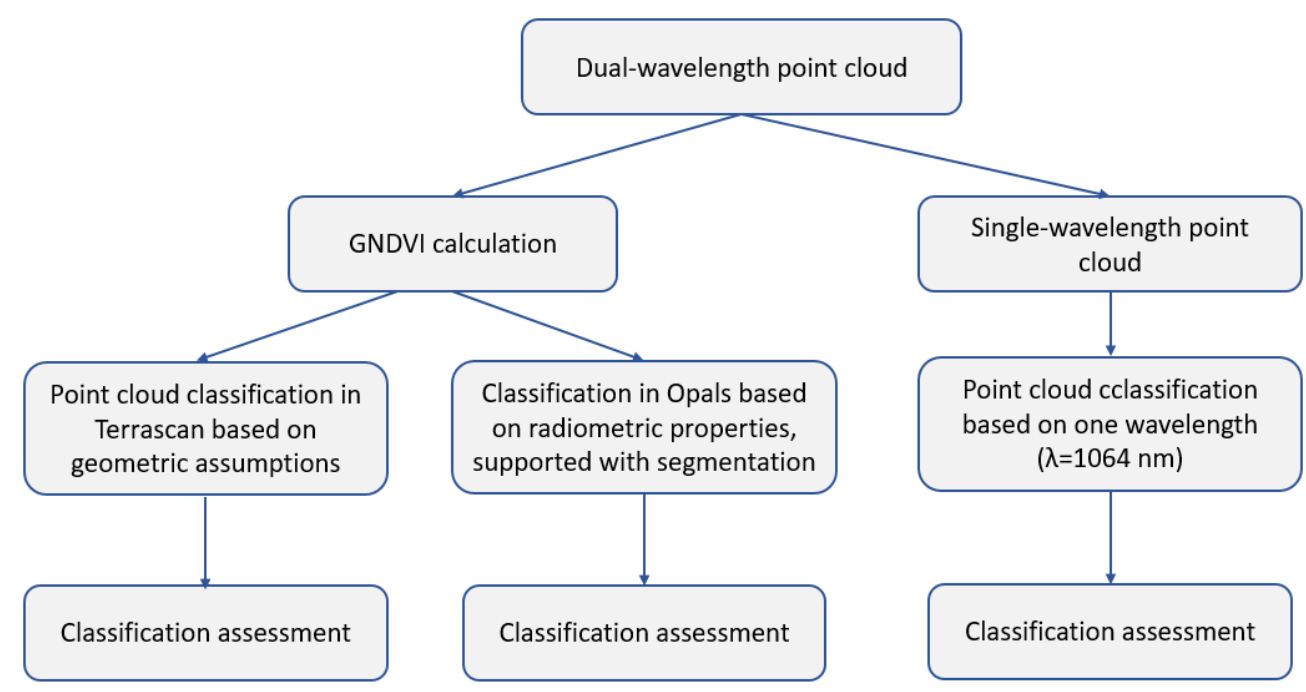

Fig. 2 Diagram shwing the classification approach proposed in the article

Within the classification approach the following classes were distinguished: ground, buildings, low, medium and vegetation. Additionally in TerraScan software low points were assigned to separate class. This classes are mostly distinguished within ALS point cloud classification. In order to create three vegetation classes, normalized height thresholds were set: $<0.4 \mathrm{~m}$ for low, $0.4-2.0 \mathrm{~m}$ for medium, and $>2.0 \mathrm{~m}$ for high vegetation.

In OPALS two classification approaches were carried out. In the first approach among all the radiometric properties of the objects were taken into consideration in both near infrared and green wavelengths. For three bands obtained for the dual-wavelength data, i.e. Red (1064 nm), Green (532 nm) and Blue (GNDVI) the intensity values for the classified objects were set after presenting the intensity as raster files. After performing the test classification with different combination of threshold values and utilized bands (R, G, B), it was concluded that the most appropriate for the classification turned out to be the GNDVI and Green channel. What may be surprising, the near infrared intensity was not directly used in the classification approach, however it was included in the Green Normalized Difference Vegetation Index.

In the second approach radiometric properties of the objects in only near infrared wavelength were considered. The near infrared wavelength was chosen in the single-wavelength classification approach because most of the single-wavelength airborne laser scanners operate in this part of the spectrum. In this approach echoes registered by the green laser scanner were also used after assigning the intensity values in NIR channel from the nearest neighbour from the second laser scanner. As a result, there was the same point density in all classification approaches. Additionally, in order to distinguish some of the classes (e.g. high and low vegetation), the normalized height was used. The Digital Terrain Model (DTM) was generated from the reference ALS data and for each echo the normalized height was calculated, which was a difference between the registered height and the terrain height from the DTM. As a reference ALS data a point cloud obtained within a national project was used.

The results of the classifications conducted in TerraScan and OPALS program were compared to the manual classification. The manual classification consists in improvement the classification conducted in TerraScan. The full classification approach which was examined in this article is presented in the Figure 2.

\section{RESULTS}

Conducted classification processes showed that algorithms in the TerraScan software classify the point cloud with the accuracy of 86\% comparing with the manual classification. However, the Opals classification with the usage of radiometric properties and some geometric properties like normalized height gives comparable results to the TerraScan automatic classification. The dual-wavelength classification accuracy was approximately $81 \%$. In TerraScan software there were less points classified as ground than in the dual-wavelength classification. Especially the streets was not fully classified as ground in TerraScan (Fig. 3). Additionally, in the right down corner, where high vegetation class predominates orange points are visible on classification image, which should be assigned to high vegetation class instead of building class.

The geometric classification in TerraScan does not allow to distinguish ground and grass properly. The dual-wavelength classification in OPALS makes it possible to assign point to ground and grass classes more properly. However, there are some areas in which the ground class could have been overestimated. Nevertheless, in this study the radiometric information about the registered objects was successfully used in point cloud classification approaches.

Further, the classification approach with the usage of the intensity registered in two wavelengths gives noticeable better results than the classification with the usage of the intensity in one wavelength. In the Figure 4 results of the dual- and singlewavelength classification are presented. In the single-wavelength approach there was a problem with proper classification of buildings and trees. Information in near-infrared channel seemed to be not enough. Some building point were classified as high vegetation and vice versa. Moreover, there was also a problem with distinguishing low vegetation from ground and roads. However, the road was classified more correctly than in TerraScan Software. 


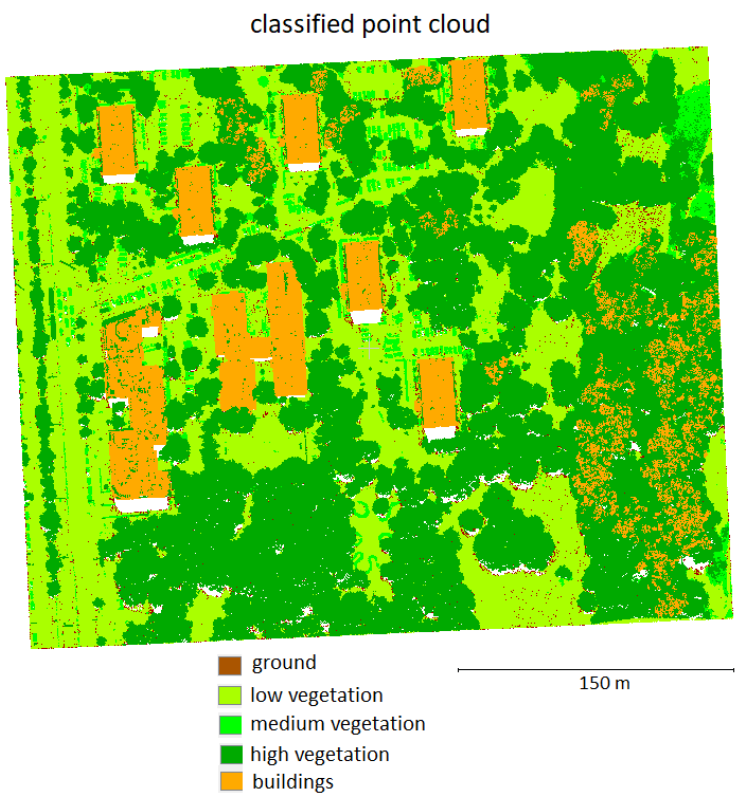

Fig. 3 Reslts of the classification in TerraScan. The asphalt was classified as low vegetation

single-wavelength classification

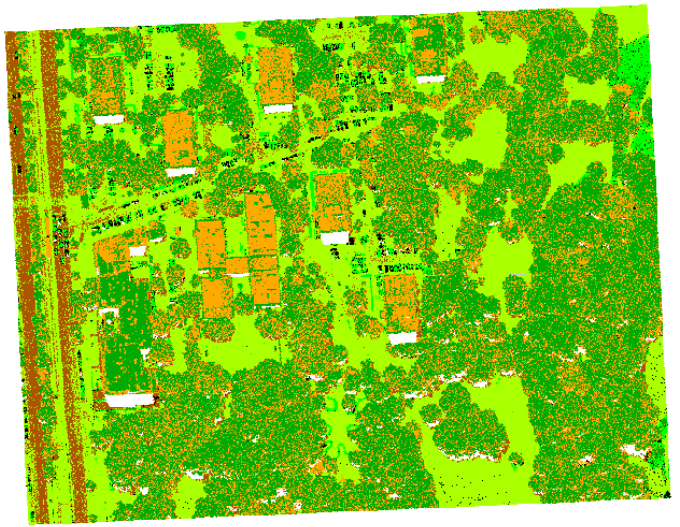

dual-wavelength classification

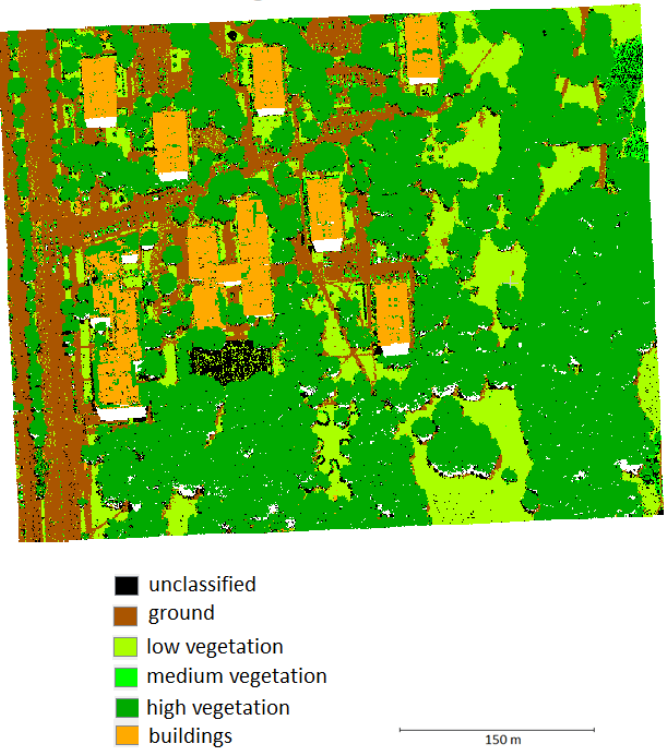

Fig. 4 Visual comparison of single- and dual-wavelength classification based on radiometric information

\section{STREET CLASSIFICATION}

Multispectral LiDAR data can be also used in more detailed classification of registered objects. Until now one of the best known applications is tree species classification (Axelsson et al. 2018). However, intensity registered in two or even three channels makes it possible to classify other objects. In the Figure 5 a possibility of street classification from dual-wavelength intensity is presented. The classification was conducted in OPALS software and TerraScan. In OPALS the following point features were included: RGB channels, echo (single), and flatness of the terrain $\left(\sigma_{0}-\right.$ standard deviation of height).

The road classification results which are presented in the Figure 5 are satisfactory. For the dual-wavelength classification there are some points between the roads which should not be assigned to this class, however comparing to the TerraScan results is it still possible to indicate the road sketch. In some areas where street lines are interrupted, it may be caused among all by trees which grow near the street. The crowns of the trees makes the laser beam difficult to penetrate if the ALS data are obtained during leaf-on condition. If the point occurs on the ground, it does not fulfil the "single echo" requirement of the OPALS classification. Further, the road classification algorithm which is implemented in TerrasScan software may also base on some linear assumption, therefore there are not many interruptions are noticeable. However, there are also places where points which are not streets were assigned to this class.

\section{Dual-wavelength roads}
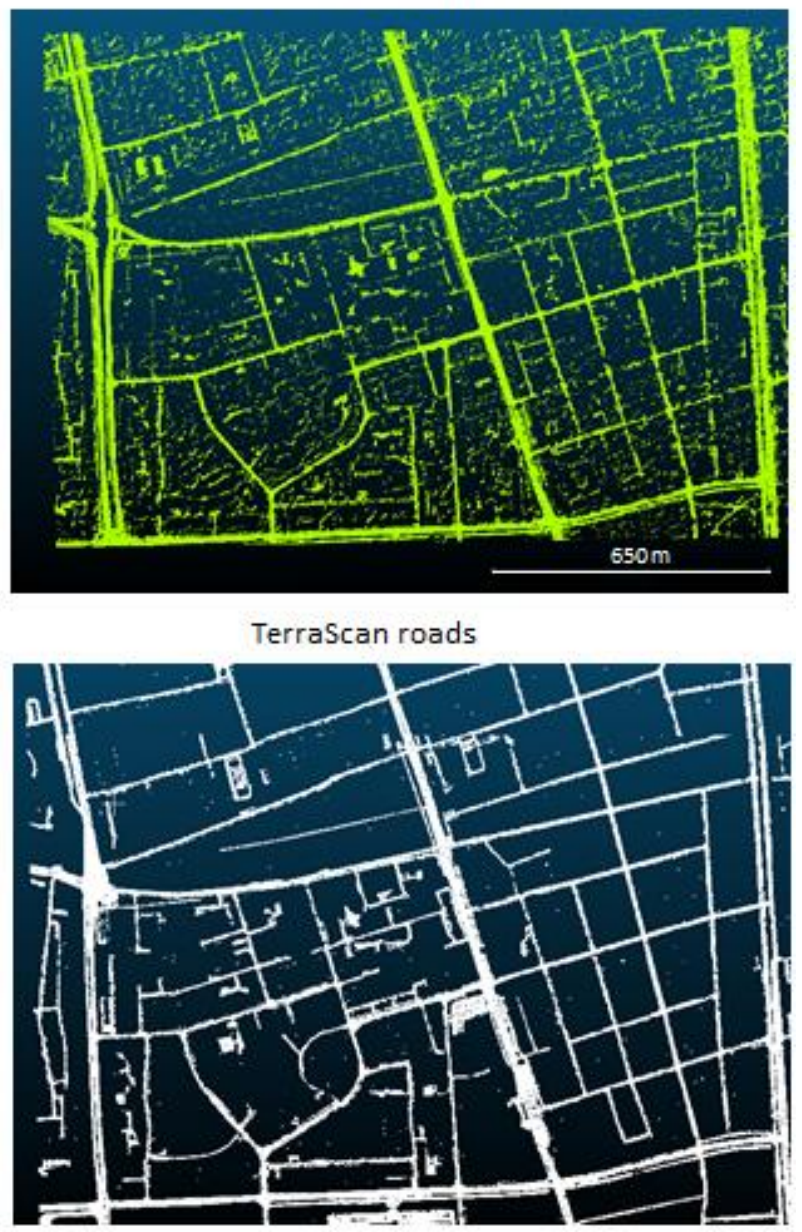

Fig. 5 Results of the road classification based on the dualwavelength intensity information in OPALS and in TerraScan software 


\section{CONCLUSION}

In this article three classification approaches are presented. The first classification was conducted in TerraScan software and was based on the geometric features. In two another approaches the radiometric properties of the objects in two and one wavelength accordingly were used. Additionally, in this approaches the normalized height was used in order to distinguish middle, low and high vegetation, and also to single out ground and buildings.

According to the classification results in can be noticed that classification in TerraScan characterizes with the highest overall accuracy equal $86 \%$. The dual-wavelength classification's over accuracy was $81 \%$ and the single-wavelength: $58 \%$. The overall accuracy of dual-wavelength classification was slightly worse that the results obtained in TerraScan. However, it need to be stressed that in TerraScan classification dedicates algorithms are implemented, what might have improved the final results.

The radiometric-based classifications were conducted in OPALS software. The classifications consisted in assigning points to classes based on values of GNDVI and intensity in green channel. This approach was rather a point-based one, i.e. points were assigned to classes based on the radiometric features and normalized height of individual points without analysing the neighbourhood. Additionally for more accurate building classification, because of different roof types, segments were created based on the geometric properties of the roofs.

According to the confusion matrices which are provided in the appendix, in TerraScan software ground was classified more accurate. However, in both OPALS and TerraScan there were problems with proper classification of the low vegetation (class 3 ), what still seems to be a challenge. Completeness of the low vegetation classification was similar for dual-wavelength and TerraScan software. However, the ground class was more completely classified in TerraScan, what can be also noticed on the provided DTMs which were generated from the ground class provided by dual-wavelength and TerraScan classification. In the Figure 6 it can be noticed that the TerraScan DTM is more smooth, both in the areas where buildings are and where the high vegetation grows. For building and high vegetation class the correctness and completeness was comparable in dualwavelength and TerraScan classification.

The single-wave classification gives much lower results than the geometric and dual-wavelengths approaches. Intensity in one wavelength can be used in the point classification approach as additionally feature. Additionally, after applying some extra assumptions, e.g. normalized vegetation, simple segmentation, it is possible to obtain results which are comparable to the geometric classification.

The performed studies showed that multi-wavelength laser scanning has a great potential not only to be used in land cover classification as $2 \mathrm{D}$ representation, but also in $3 \mathrm{D}$ point cloud classification. Additionally, based on the road classification it can be noticed that the possibility of more detailed classification, not only concerning the tree species, but also urban objects like streets.

\section{ACKNOWLEDGEMENTS}

The author would like to thank the OPEGIEKA Sp. z o. o. company for providing the data.

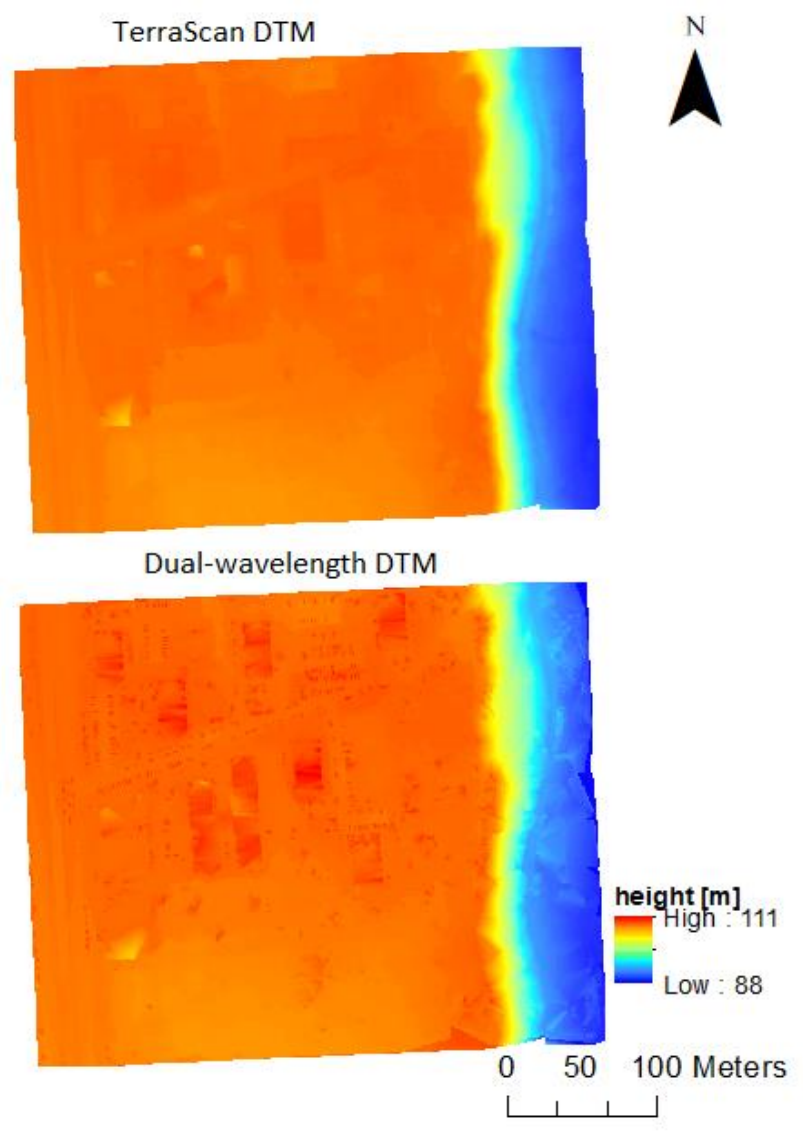

Fig. 6 Comparison of the DTMs generated from the ground class obtained from TerraScan and dual-wavelength classification

\section{REFERENCES}

Axelsson, A., Lindberg, E., \& Olsson, H. (2018). Exploring Multispectral ALS Data for Tree Species Classification. Remote Sensing, 10(2), 183.

Bakuła, K., 2015. Multispectral airborne laser scanning-a new trend in the development of LiDAR technology. Archiwum Fotogrametrii, Kartografii i Teledetekcji, vol. 27, s. 25-44.

Bakuła, K., Kupidura, P., Jełowicki, Ł., 2016. Testing of land cover classification from multispectral airborne laser scanning data. International Archives of the Photogrammetry, Remote Sensing \& Spatial Information Sciences, XLI-B7, 161-169.

Baltsavias, E. P., 1999. Airborne laser scanning: basic relations and formulas. In: ISPRS Journal of photogrammetry and remote sensing, 54(2-3), 199-214.

Doneus, M., Miholjek, I., Mandlburger, G., Doneus, N., Verhoeven, G., Briese, C., \& Pregesbauer, M., 2015. Airborne laser bathymetry for documentation of submerged archaeological sites in shallow water. The International Archives of Photogrammetry, Remote Sensing and Spatial Information Sciences, 40(5), 99.

Irish, J. L., \& Lillycrop, W. J., 1999. Scanning laser mapping of the coastal zone: the SHOALS system. ISPRS Journal of Photogrammetry and Remote Sensing, 54(2-3), 123-129. 
Kaasalainen, S., Pyysalo, U., Krooks, A., Vain, A., Kukko, A., Hyyppä, J., \& Kaasalainen, M., 2011. Absolute radiometric calibration of ALS intensity data: Effects on accuracy and target classification. Sensors, 11(11), 10586-10602.

Matikainen, L., Hyyppä, J., \& Litkey, P., 2016. Multispectral airborne laser scanning for automated map updating. ISPRS Journal of Photogrammetry and Remote Sensing, 128, 298-313.

Pfeifer, N., Mandlburger, G., Otepka, J., Karel, W.,2014. OPALS - A framework for Airborne Laser Scanning data analysis. Computers, Environment and Urban Systems, 45, 125 - 136.

Pfennigbauer, M., \& Ullrich, A., 2011. Multi-wavelength airborne laser scanning. In Proceedings of the International LiDAR Mapping Forum, ILMF, New Orleans.

International Archives of the Photogrammetry, Remote Sensing \& Spatial Information Sciences, 41.

Matikainen, L., Karila, K., Hyyppä, J., Litkey, P., Puttonen, E., Ahokas, E., 2017. Object-based analysis of multispectral airborne laser scanner data for land cover classification and map updating. ISPRS Journal of Photogrammetry and Remote Sensing, 128, 298-313.

Pilarska, M., 2016. Radiometric calibration of airborne laser scanning data. In: Archiwum Fotogrametrii, Kartografii $i$ Teledetekcji, vol. 28, pp. 79-90
Sun, J., Shi, S., Chen, B., Du, L., Yang, J., \& Gong, W. (2017, July). Combined application of 3D spectral features from multispectral LiDAR for classification. In Geoscience and Remote Sensing Symposium (IGARSS), 2017 IEEE International (pp. 5264-5267).

van Rees, E., 2015. The first multispectral airborne LiDAR sensor. GeoInformatics, 18(1), 10.

Wehr, A., \& Lohr, U., 1999. Airborne laser scanning-an introduction and overview. ISPRS Journal of photogrammetry and remote sensing, 54(2-3), 68-82.

Wichmann, V., Bremer, M., Lindenberger, J., Rutzinger, M., Georges, C., \& Petrini-Monteferri, F., 2015. Evaluating the potential of multispectral airborne LiDAR for topographic mapping and land cover classification. ISPRS Annals of Photogrammetry, Remote Sensing \& Spatial Information Sciences, 2.

Yan, W. Y., \& Shaker, A., 2014. Radiometric correction and normalization of airborne LiDAR intensity data for improving land-cover classification. IEEE Transactions on Geoscience and Remote Sensing, 52(12), 7658-7673.

\section{APPENDIX}

Table 1 Confusion matrix and accuracy estimates for the dual-wavelength classification

\begin{tabular}{|r|r|r|r|r|r|r|r|r|r|}
\hline manual & unclassified & ground & low veg. & $\begin{array}{c}\text { middle } \\
\text { veg. }\end{array}$ & $\begin{array}{l}\text { high } \\
\text { veg. }\end{array}$ & building & $\begin{array}{c}\text { low } \\
\text { points }\end{array}$ & $\begin{array}{c}\text { Completeness } \\
{[\%]}\end{array}$ & $\begin{array}{c}\text { Overall } \\
\text { Accuracy } \\
{[\%]}\end{array}$ \\
\hline unclassified & 45 & 105653 & 116330 & 23644 & 7572 & 6958 & 54 & 0.02 & 80.756 \\
\hline ground & 6 & 392039 & 98976 & 7268 & 404 & 1622 & 15 & 76.36 & Kappa \\
\hline low veg. & 1 & 146533 & 259355 & 2465 & 282 & 42 & 2 & 63.45 & 0.81 \\
\hline middle veg. & 3 & 55 & 114 & 38940 & 452 & 832 & 0 & 79.01 \\
\hline high veg. & 145 & 780 & 3091 & 696 & 1716108 & 59442 & 1 & 96.40 \\
\hline building & 10 & 35 & 35 & 17 & 8268 & 185722 & 0 & 95.69 \\
\hline low points & 0 & 0 & 0 & 0 & 0 & 0 & 0 & 0.00 \\
\hline $\begin{array}{l}\text { Correctness } \\
{[\%]}\end{array}$ & 21.43 & 60.77 & 54.27 & 53.32 & 99.02 & 72.94 & 0 & \\
\hline
\end{tabular}

Table 2 Confusion matrix and accuracy estimates for the TerraScan classification

\begin{tabular}{|r|r|r|r|r|r|r|r|r|r|}
\hline manual & unclassified & ground & low veg. & $\begin{array}{c}\text { middle } \\
\text { veg. }\end{array}$ & $\begin{array}{l}\text { high } \\
\text { veg. }\end{array}$ & building & $\begin{array}{c}\text { low } \\
\text { points }\end{array}$ & $\begin{array}{c}\text { Completeness } \\
\text { [\%] }\end{array}$ & $\begin{array}{c}\text { Overall } \\
\text { Accuracy } \\
{[\%]}\end{array}$ \\
\hline unclassified & 210 & 0 & 0 & 0 & 0 & 0 & 0 & 100.00 & 86.021 \\
\hline ground & 0 & 363545 & 129 & 46 & 708 & 33 & 0 & 99.75 & Kappa \\
\hline low veg. & 0 & 280619 & 476866 & 66 & 875 & 30 & 0 & 62.87 & 0.86 \\
\hline middle veg. & 0 & 85 & 64 & 72673 & 263 & 2843 & 0 & 71.38 \\
\hline high veg. & 0 & 836 & 835 & 239 & 1666964 & 70852 & 0 & 95.82 \\
\hline building & 0 & 10 & 7 & 6 & 64276 & 180860 & 0 & 73.77 \\
\hline low points & 0 & 0 & 0 & 0 & 0 & 0 & 72 & 100.00 \\
\hline $\begin{array}{l}\text { Correctness } \\
\text { [\%] }\end{array}$ & 100.00 & 56.36 & 99.78 & 99.51 & 96.18 & 71.03 & 100.00 & \\
\hline
\end{tabular}


The International Archives of the Photogrammetry, Remote Sensing and Spatial Information Sciences, Volume XLII-2, 2018 ISPRS TC II Mid-term Symposium “Towards Photogrammetry 2020”, 4-7 June 2018, Riva del Garda, Italy

Table 3 Confusion matrix and accuracy estimates for the single-wavelength classification

\begin{tabular}{|r|r|r|r|r|r|r|r|r|r|}
\hline manual & unclassified & ground & low veg. & $\begin{array}{c}\text { middle } \\
\text { veg. }\end{array}$ & $\begin{array}{l}\text { high } \\
\text { veg. }\end{array}$ & building & $\begin{array}{c}\text { low } \\
\text { points }\end{array}$ & $\begin{array}{c}\text { Completeness } \\
\text { [\%] }\end{array}$ & $\begin{array}{c}\text { Overall } \\
\text { Accuracy } \\
{[\%]}\end{array}$ \\
\hline unclassified & 6 & 1037 & 3110 & 16769 & 486 & 1308 & 3 & 0.02 & 58.023 \\
\hline ground & 22 & 172164 & 87300 & 101 & 909 & 28 & 33 & 66.07 & Kappa \\
\hline low veg. & 24 & 470978 & 384140 & 5410 & 1024 & 174 & 35 & 44.56 & 0.58 \\
\hline middle veg. & 0 & 81 & 193 & 50030 & 297 & 1422 & 0 & 75.12 \\
\hline high veg. & 78 & 484 & 1850 & 440 & 1116092 & 111643 & 1 & 90.70 \\
\hline building & 80 & 351 & 1308 & 280 & 614278 & 140043 & 0 & 18.52 \\
\hline $\begin{array}{l}\text { low points } \\
{[\%]}\end{array}$ & 0 & 0 & 0 & 0 & 0 & 0 & 0 & 0.00 \\
\hline
\end{tabular}

